\title{
Alternative flaps in autologous breast reconstruction
}

\author{
Paige L. Myers, Jonas A. Nelson, Robert J. Allen Jr \\ Memorial Sloan Kettering Cancer Center, New York, NY, USA \\ Contributions: (I) Conception and design: All authors; (II) Administrative support: JA Nelson, RJ Allen Jr; (III) Provision of study materials or patients: \\ JA Nelson, RJ Allen Jr; (IV) Collection and assembly of data: All authors; (V) Data analysis and interpretation: All authors; (VI) Manuscript writing: \\ All authors; (VII) Final approval of manuscript: All authors. \\ Correspondence to: Robert J. Allen Jr. Memorial Sloan Kettering Cancer Center, 1275 York Ave., New York, NY 10065, USA. Email: allenr1@mskcc.org.
}

\begin{abstract}
The gold standard for autologous reconstruction in the post-mastectomy patient remains the deep inferior epigastric artery perforator flap, although many women may not be candidates for abdominally based free tissue transfer. In this scenario, there are several other donor site options based from the thigh (transverse and diagonal upper gracilis flaps, profunda artery perforator flap, lateral thigh flap) and trunk (lumbar artery perforator flap, superior and inferior gluteal artery perforator flaps). This study will review the history, relevant anatomy, surgical technique and outcomes for alternative flaps in autologous reconstruction. Additionally, preoperative imaging (CTA, MRA) and novel applications (stacking flaps, neurotization) in breast reconstructive microsurgery will be discussed.
\end{abstract}

Keywords: Microsurgery; breast reconstruction; autologous tissue reconstruction

Submitted Feb 06, 2020. Accepted for publication Feb 28, 2020.

doi: $10.21037 / g s .2020 .03 .16$

View this article at: http://dx.doi.org/10.21037/gs.2020.03.16

\section{Introduction}

Reconstructive surgery is a fundamental element in the care of breast cancer patients. This is commonly accomplished through either implant-based or autologous reconstruction following mastectomy. While rates of implant-based reconstruction remain high (1), autologous free tissue transfer offers several benefits in the appropriate patient (2). Specifically, autologous reconstruction has been shown to provide for a more natural, ptotic appearance of the breast with longer lasting results and improved patient satisfaction compared to implants (3).

The first abdominally based method for autologous breast reconstruction described by Hartrampf was the pedicled transverse rectus abdominis muscle (TRAM) flap, which relied on the superior epigastric vessels (4). As the field of microsurgery began to evolve, Holmström et al. and Grotting et al. popularized the free TRAM flap $(5,6)$, based on the dominant inferior epigastric vessels, offering many advantages such as more robust perfusion, less fat necrosis and increased freedom of shaping (7). As knowledge of perforator anatomy expanded and techniques of microsurgery flourished, the deep inferior artery epigastric perforator (DIEP) flap was designed to preserve the rectus abdominis muscle, decreasing donor site morbidity associated with TRAM flaps (8-10). Since its description (8), the DIEP flap has become the gold standard for autologous breast reconstruction. Unfortunately, some patients are not candidates for this procedure secondary to a lack of volume at the donor site or previous abdominal surgery (11). For this subset of patients seeking autologous reconstruction, other donor sites are needed. Herein, we will explore alternative autologous options for breast reconstruction from the thigh, buttock and flanks in terms of flap history, relevant anatomy, surgical technique as well as outcomes. We will also discuss current technologies that improve flap design, expedite surgical harvest and ensure soft tissue viability.

\section{Preoperative imaging}

Computed topographic angiography (CTA) or magnetic resonance angiography (MRA)

Increasing improvements and complexity in microsurgical 


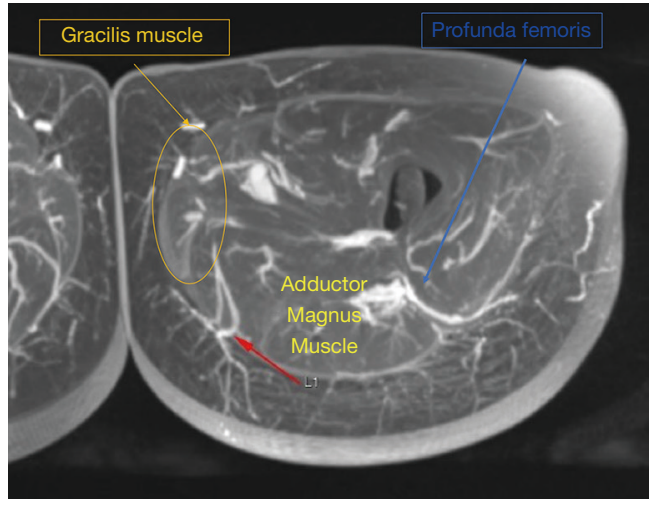

Figure 1 MRA showing profunda artery perforator (red arrow). Reference points are the midline, gluteal crease and posterior border of the gracilis muscle. Imaging assists in not only finding the location of the perforator of choice, but also the course it takes to the source vessel. MRA, magnetic resonance angiography.

reconstruction have been aided by several technological advancements. Sophisticated imaging modalities have allowed for precise planning of autologous donor site vascular anatomy with the goal of defining the perforator(s) diameter, course, and length of the pedicle (12). The two most common types of imaging are CTA and MRA. These modalities are less invasive and require less user subjectivity compared to conventional angiography and ultrasonography, respectively (13-15). Especially useful in the oncologic patient, imaging may detect important incidental findings in the abdomen and pelvis, such as metastatic disease. Each type has their disadvantages as well. The patient is subject to radiation to obtain CTA imaging. While MRA does not involve ionizing radiation, this technique is more costly and may not be widely accessible or available to all patients (7).

Preoperative imaging allows for a detailed depiction of the donor vessel(s) anatomy in relation to soft tissue structures as a reference point, such as the umbilicus or gluteal crease. Based on this information, the surgeon can expertly design flaps based on preoperatively determined perforators that limit patient morbidity (i.e., those with a shorter intramuscular or no intramuscular course) and approach key perforators quickly to improve efficiency and decision-making intraoperatively (Figure 1). Additional benefits of preoperative imaging include volumetric analysis of donor and recipient sites (Figure 2) and being an adjunct tool in the training of residents and fellows $(7,16,17)$. With regards to autologous breast reconstruction, imaging provides the surgeon with a more accurate assessment of available donor site tissue to reconstruct the breast following mastectomy, potentially alerting the clinician to the need for additional volume in the form of extended or additional flaps $(18,19)$.

\section{Indocyanine Green (ICG) angiography}

ICG angiography is another imaging modality for use in autologous breast reconstruction. ICG angiography is commonly performed with the SPY fluorescence imaging system (NOVADAQ Technologies, Inc., Mississauga, Ontario Canada) and has greatest utility in the assessment of intraoperative perfusion of donor site tissues and mastectomy skin flaps (20-22). Once a flap is isolated on its perforator(s), intravenous injection of ICG can be visualized in the vasculature of the tissues using infrared fluorescence. When used for perforator selection, clamps can be placed on less favorable perforators to ensure adequate perfusion on the chosen vessels. Additionally, the SPY system will show areas of relative underperfusion, such as tissue zones distal to the perforators or areas of tissue near previous scars, which can then be excised to decrease the risk of eventual fat necrosis (7). Another helpful application of ICG fluorescent imaging is to evaluate the perfusion of mastectomy skin flaps. The relative perfusion of mastectomy skin flaps can alert the clinician to the necessity (or lack thereof) of removing additional mastectomy skin and replacing this with donor site skin. To this extent, ICG angiography can reduce the rates of mastectomy skin flap necrosis, reducing patient morbidity and improving cosmetic results (7).

In part, the advancements in preoperative imaging have not only helped broaden our repertoire of flaps for use in autologous breast reconstruction but also improved our results as they relate to patient morbidity and cosmetic outcomes. The following are some examples of alternative options for breast reconstruction from the thighs and trunk.

\section{Thigh-based flaps}

\section{Transverse upper gracilis (TUG) Flap}

Originally, the TUG flap for breast reconstruction was described by Yousif et al. (1992) due to the transverse orientation of skin to muscle fibers (23). The ideal patients are women with small to moderate breast size (only 250 $400 \mathrm{cc}$ per flap) (11) and excess adiposity in their medial 


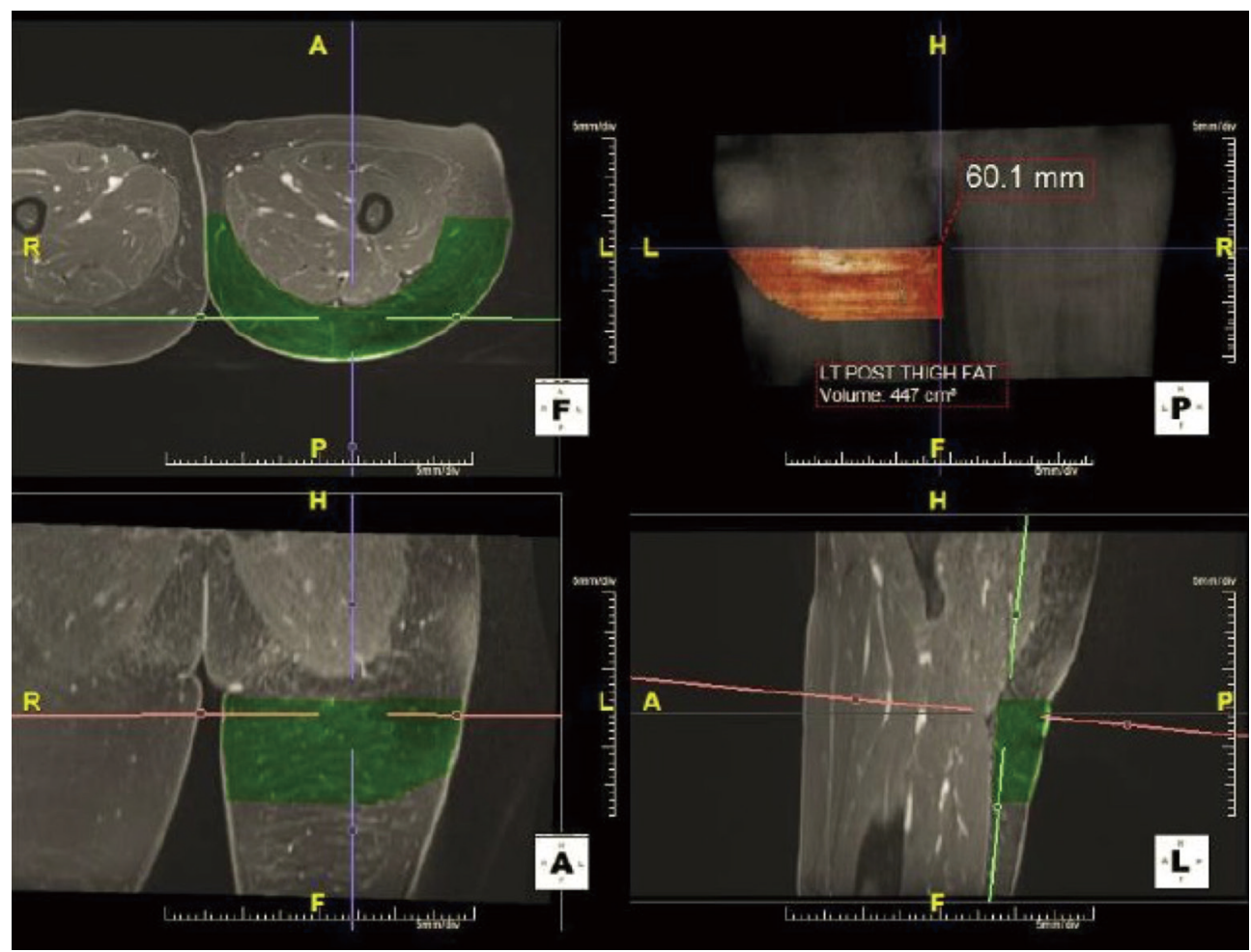

Figure 2 MRA showing volumetric analysis of left PAP flap (447g for a $6 \mathrm{~cm} \times 22 \mathrm{~cm}$ flap). MRA, magnetic resonance angiography.

thighs. The dominant pedicle to the TUG flap is the ascending medial femoral circumflex artery with two venae comitantes. Its measured length is $6-10 \mathrm{~cm}$ and diameter averages $1.6 \mathrm{~mm}$ (24). The pedicle enters the proximal third of the gracilis muscle approximately $10 \pm 2 \mathrm{~cm}$ distal to the pubic tubercle (24). The course of the gracilis muscle can be identified with a line drawn from pubic symphysis to medial tibial condyle along the medial thigh. Alternatively, the axis can be found by palpating the adductor longus (AL) muscle medially with the thigh abducted. The gracilis axis is defined 2-3 finger breadths posterior to AL edge. Using Doppler ultrasound, perforators are identified 8-12 cm distal to the pubic symphysis $(24,25)$. A pinch test is used to determine the inferior border of the flap, with the superior border within 1-4 cm of the groin crease, depending on the location of the pedicle. A crescent shape is then designed with one tip in the lateral anterior groin, approximately $2-5 \mathrm{~cm}$ anterior to gracilis pedicle, and the other in the middle of the proximal posterior thigh. Using these markings the average flap width is $6-8 \mathrm{~cm}$ (25).

The TUG flap is raised from anterior to posterior. The AL muscle is identified and its fascia incised. The AL muscle is distracted anteriorly, revealing the pedicle to the gracilis muscle. Once identified, the pedicle can be dissected under loupe magnification. Following dissection of the pedicle, the remainder of the AL fascia is opened extending distally to the tendinous portion of the gracilis muscle. The gracilis muscle is then divided at its musculotendinous junction, and the remaining incisions are made. The TUG flap is isolated on its pedicle, taking care to ensure inclusion of the AL fascia anteriorly, as skin perforators are commonly found in this septum. Additional musculocutaneous perforators supply the skin and fat of this flap, so every effort is made to avoid dissection superficial to the gracilis muscle.

The TUG flap is the most commonly utilized alternative flap for breast reconstruction with reliable outcomes and high patient satisfaction (25). Nonetheless, there are disadvantages to this flap that may prevent its use. Given the transverse orientation of the design, there is a limited amount of skin and soft tissue available. There is also a relatively short pedicle, reported between $5-7 \mathrm{~cm}$ in the literature (24-29). Excessive tension on the skin may result in wound dehiscence and scar migration with reported rates as high as $27 \%$ and $78 \%$, respectively (30-32). Additional limitations of the flap include: sacrifice of a functional muscle, potential for labial spreading, and risk 


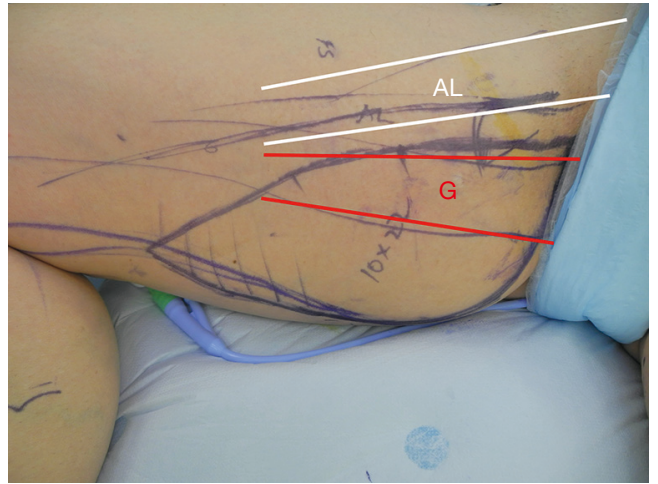

Figure 3 Preoperative markings for DUG flap. Note the reference points of the adductor longus (AL) and gracilis (G) muscles. DUG, diagonal upper gracilis.

of lymphedema $(30,32)$. One potential complication that deserves special attention when describing this flap is the risk for lower extremity lymphedema. This can result with over dissection of the flap anteriorly, as the anterior border of the flap is frequently placed close to or over the femoral triangle, which houses the major lymphatic drainage of the lower extremity. Remaining in a superficial plane while limiting anterior dissection in this area is key to preventing this devastating complication (33) and will also minimize anterior scar visibility. Another potential complication is sensory loss, occurring in approximately $11 \%$ of patients (30-32). Despite these risks, the TUG flap has been found to be a reliable option for breast reconstruction in the right patient.

\section{Diagonal upper gracilis (DUG) flap}

To make up for some of the limitations encountered with using the TUG flap, Dayan et al. described the DUG flap in 2013 (34). This design increases the amount of skin and fat available for breast reconstruction while keeping the superior two-thirds of the incision concealed in the medial thigh $(25,34)$. Importantly, the orientation of the flap along Langer's lines imposes the least tension on the closure to allow for optimal wound healing, decreases the risk for labial spreading and results in a scar that can be easily avoided with the patient sitting postoperatively. To mark the flap, the patient is first placed in the frog-legged position. First, the anterior incision is marked along the posterior border of the adductor longus, starting from the groin crease and extending $8-10 \mathrm{~cm}$ inferiorly. At this point, the line travels posteriorly in a curvilinear fashion along the relaxed skin tension lines to end in the midpoint of the posterior thigh. A pinch test is performed to determine appropriate flap width, up to $13 \mathrm{~cm}(25)$, and the posterior markings complete the ellipse that marks the DUG flap (Figure 3). With experience, the flap harvest can be facile and expeditious. As previously described, the dissection begins along the proximal anterior incision. Dissection proceeds through the adductor longus fascia. The adductor longus is retracted anteriorly to reveal the gracilis pedicle. The pedicle dissection is carried proximal for $6-8 \mathrm{~cm}$. Once isolated, the remaining skin incisions are made. The gracilis muscle is divided at its musculotendinous junction, and the flap pedicle can be divided for transfer to the chest. The donor site is closed primarily in a layered fashion over a closed suction drain. The ipsilateral flap is used for reconstruction, as this allows for the pedicle to be in an ideal location for anastomosis to the internal mammary vessels. Postoperatively, there are no restrictions on the donor site other than standard incisional care.

The DUG flap offers a nice alternative to the TUG flap and has been shown to be a reliable option (25). Dayan reports the largest series of DUG flaps for breast reconstruction. Over 6 years, 60 flaps were performed with an average flap width of 10.3 (ranging from $8-13 \mathrm{~cm}$ ). Only one patient developed $20 \%$ distal flap necrosis in an attempt to re-design the distal end of the flap more anteriorly to minimize visibility of the posterior thigh scar. The overall incidence of donor site complications was $10 \%$ without any wound dehiscences. There were 2 small local abscesses at the donor site, and 2 patients with cellulitis, one of which had a seroma (25).

The disadvantages of the DUG flap are similar to the TUG flap in that is has a relatively short, anterior pedicle with small caliber vessels, sacrifices a muscle which can atrophy with time (loss of volume), and results in a visible scar along the medial and posterior thigh. Notably, the DUG flap lies further posterior on the thigh, and thus has a potentially decreased risk of lower extremity lymphedema when compared to the TUG flap.

\section{Profunda artery perforator (PAP) flap}

First described by Allen et al. for autologous breast reconstruction (35), the PAP flap has been gaining traction as the second-best option behind the DIEP flap (Figure 4). This flap initially was introduced in 1980 as the pedicled posterior thigh myocutaneous flap by Hurwitz and Walton (36). Later modifications by Angrigiani et al. (37) and then Song et al. (38) resulted in a perforator flap indicated for 

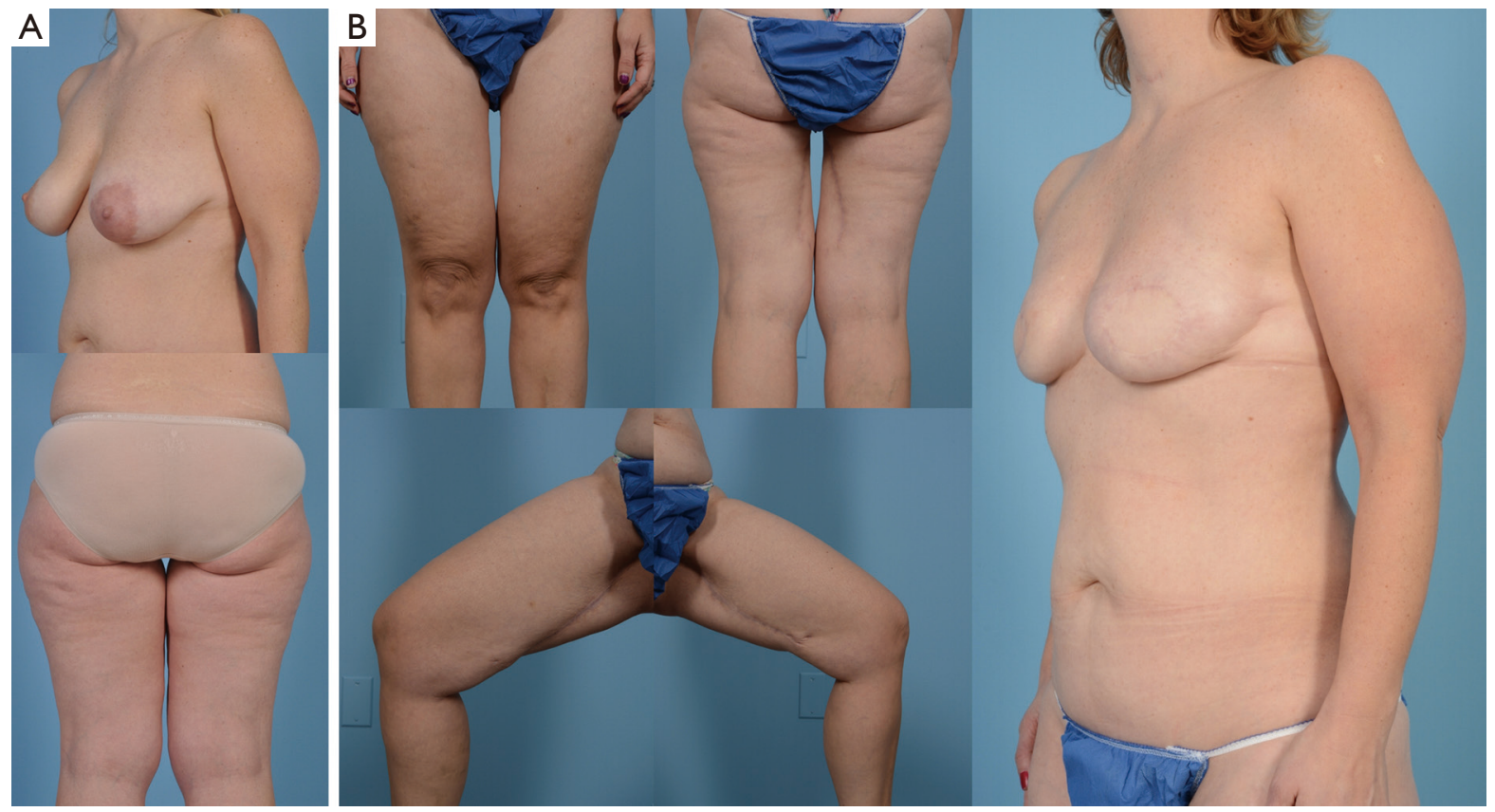

Figure 4 Preoperative (A) and 1 year postoperative (B) photos of DUG flaps for bilateral breast reconstruction.

reconstruction of pressure ulcers and lower extremity burn injury.

The PAP flap offers several advantages including an inconspicuous donor site scar, large vessels with consistent anatomy that match up well with the internal mammary vessels, a long pedicle, and a muscle-sparing alternative to the gracilis-based flaps. It is based on perforating arteries off the profunda femoris vessel that course through the adductor magnus (AM) muscle to supply the skin and fat of the proximal posterior thigh. The profunda femoris artery enters the posterior compartment of the thigh and typically gives off three main perforators. The first perforator supplies the AM and gracilis, and the second and third perforators supply the semimembranosus, biceps femoris, and vastus lateralis $(35,39)$. The flap can be oriented in the transverse, diagonal or vertical dimensions, depending on the ideal perforators identified on preoperative imaging.

In its classic description, the PAP flap is oriented in the transverse dimension. To begin, the inferior gluteal crease is marked with the patient in the standing position (Figure 5). The patient is then transitioned to the supine position on the bed, where the AL and gracilis muscles can be marked with the patient frog-legged. Next, the patient is rotated prone to mark the perforators identified on preoperative MRA, generally within $7 \mathrm{~cm}$ of the gluteal fold (35). With the landmarks identified, the flap can be designed with the anterior border located at the posterior border of the AL muscle. The superior border is at or within $2 \mathrm{~cm}$ of inferior gluteal crease extending to lateral-most portion of inferior gluteal crease. A pinch test is used to determine the width of the flap, and an ellipse is formed.

Flap harvest can be accomplished in a two-team approach with the patient in a frog-legged, lithotomy or split-leg position. Dissection begins by incising the anterior half of the flap to the posterior gracilis border. Electrocautery is used to dissect down anteriorly through the gracilis fascia, retracting the gracilis anteriorly to reveal AM fascia. This is then incised and the dissection is carried posteriorly along the AM surface until the key profunda artery perforators are identified. A standard perforator dissection ensues and is continued through muscle until adequate length and perforator size are met or until the profunda artery is reached. In most instances, it is necessary to dissect the pedicle entirely through the AM muscle before these criteria are achieved (Figure 6). Once adequate length and size are encountered, generally $10 \mathrm{~cm} \mathrm{(36),} \mathrm{the} \mathrm{pedicle} \mathrm{is} \mathrm{divided.}$ At this time, the anterior flap can be tailor-tacked back into place, leaving the flap perfused by its posterior attachments, or the remainder of the incisions can be made to harvest the flap for transfer. Once harvested, the donor site is closed in layers over a closed suction drain. The inferior thigh skin can be undermined to allow for advancement of the 


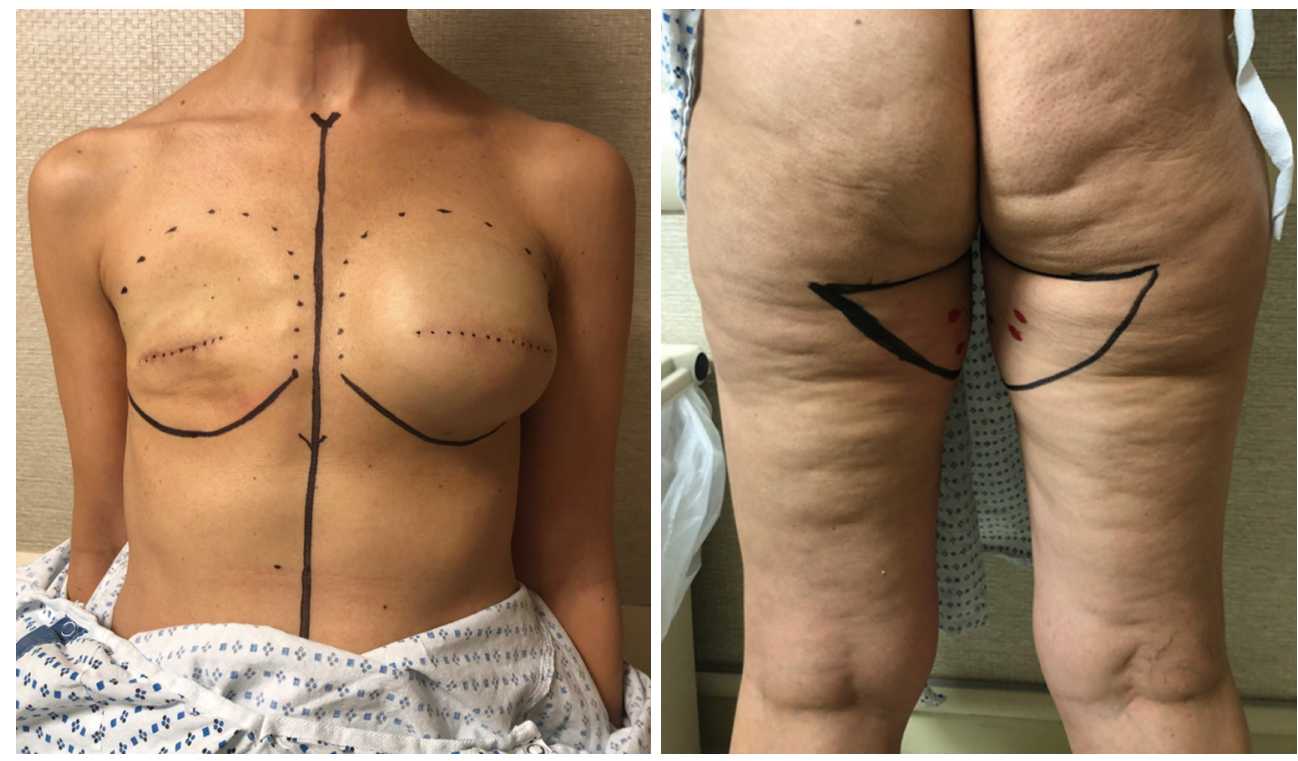

Figure 5 Preoperative photographs of bilateral PAP flaps for failed right breast tissue expander secondary to infection. The gluteal crease is marked and perforators identified based on preoperative imaging (Figure 1). PAP, profunda artery perforator.
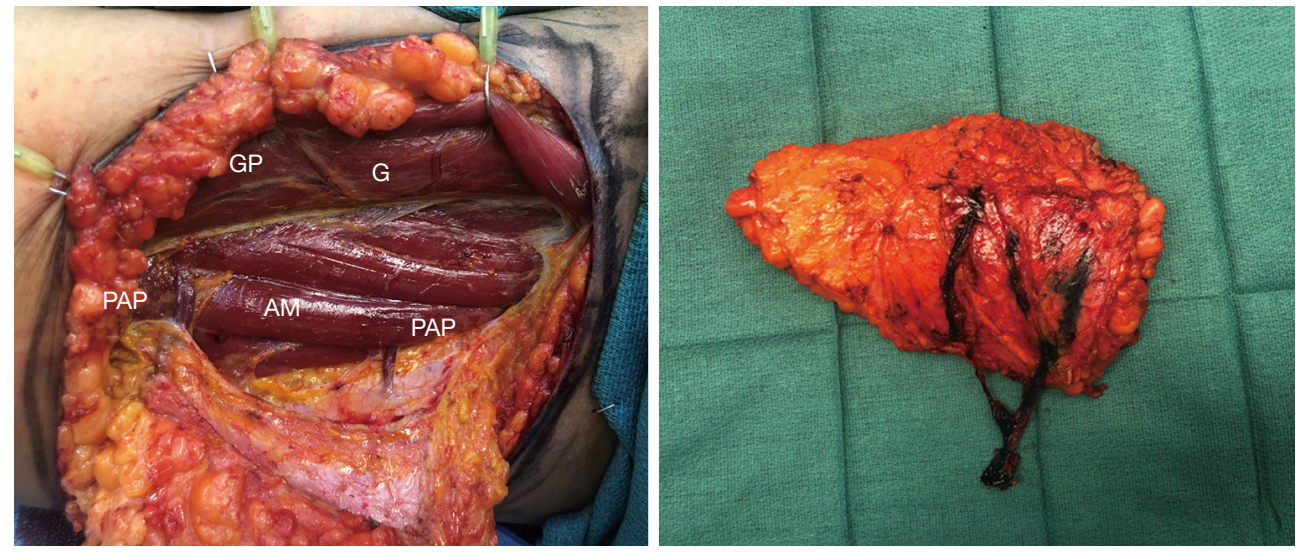

Figure 6 Intraoperative flap dissection of PAP flap. Note the relationship of the PAP to the G, its pedicle and the AM and the flap harvested weighed $430 \mathrm{~g}$ as previously predicted on imaging (Figure 2). PAP, profunda artery perforator; GP, pedicle; AM, adductor magnus; G, gracilis muscle.

subcutaneous tissues and plication to the underlying fascia. All efforts should be made to decrease tension on the final incision, as excessive tension can result in widening of the scar and flattening of the gluteal fold. The flap can be used for an ipsilateral or contralateral reconstruction given the centralized location of the perforator(s) in this flap (25) (Figure 7).

Allen Jr et al. (40) and Haddock et al. (41) report the largest series with the transversely oriented PAP flap which has proved to be reliable and effective for small to medium size breast reconstruction. In the largest published series of 164 PAP flaps for breast reconstruction, Allen Jr. et al. found the dimensions of the flap to average $27.2 \mathrm{~cm}$ in length and $6.3 \mathrm{~cm}$ in width with an average flap weight of $367.4 \mathrm{~g}$. The overall success rate of the profunda artery perforator flap was greater than $99 \%$, with only one flap loss recorded. The most common complication was fat necrosis (7\%) followed by seroma formation (6\%) (40). In 

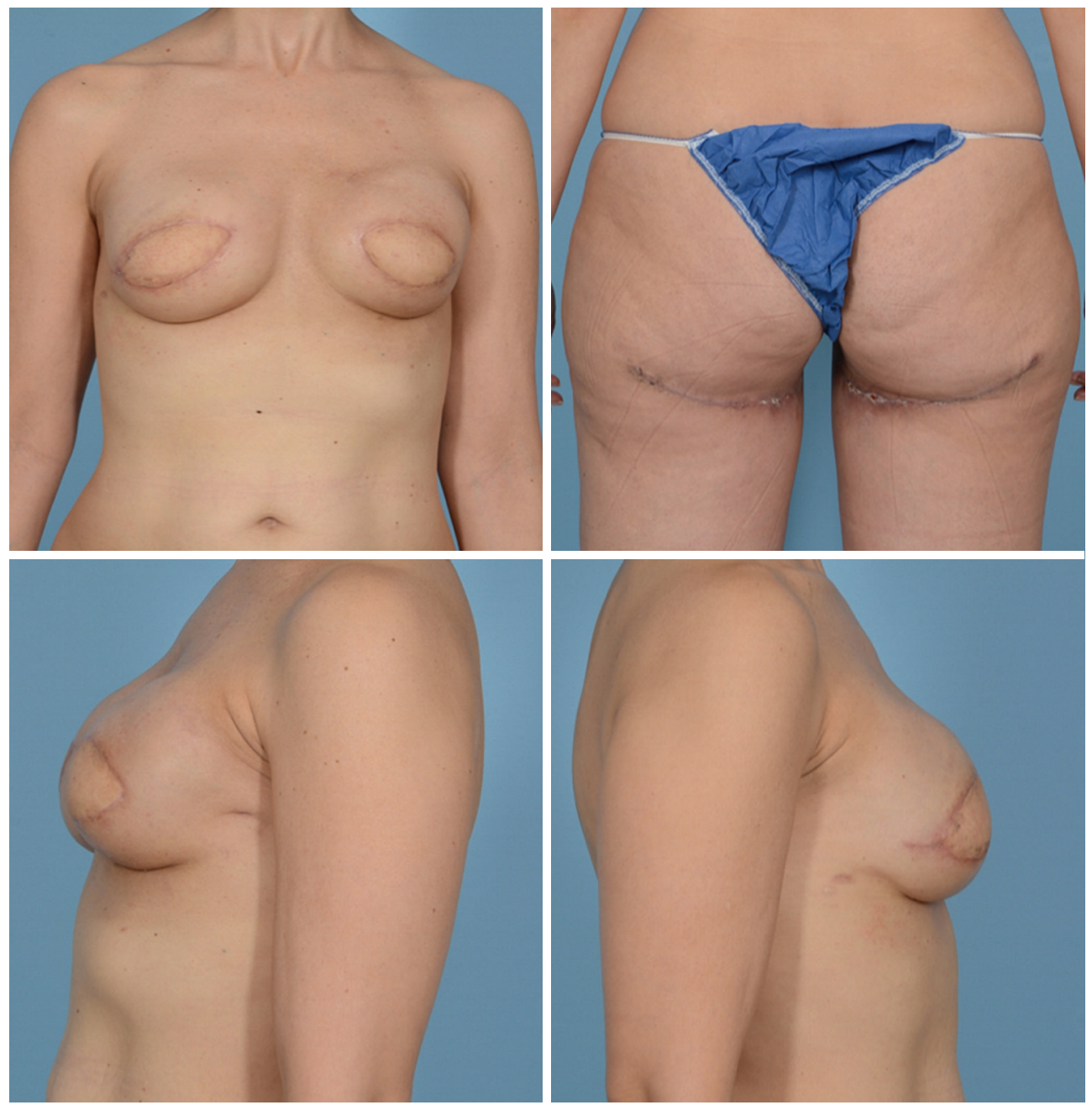

Figure 7 Postoperative photographs 6 weeks from bilateral PAP flaps. PAP, profunda artery perforator.

the series by Haddock et al., 101 flaps were performed with an average weight of $425 \mathrm{~g}$. Complications included total flap loss (2\%), donor-site cellulitis (5.9\%), and donor-site wound dehiscence (10.9\%) (41).

Despite the growing popularity of the PAP flap as the second-line option for autologous breast reconstruction, several disadvantages have been described. As the incision lies just inferior to the gluteal crease, some patients may find this painful while sitting. Additionally, the width of the skin paddle may be limited due to the transverse orientation of the scar. Finally, the posterior cutaneous nerve of the thigh may be sacrificed during dissection that alters sensation to the posterior thigh. Our postoperative protocol for the transverse PAP flap includes compression garments for 3 weeks and sitting on an elevated seat to avoid pressure to the incision (4 weeks). The compression garments aid in decreasing fluid collection in the donor site, without that, drains can be expected to stay in for up to 3 weeks. There are other options described for the skin paddle design of the PAP flap to take advantage of redundancy of inner thigh tissue. The vertical PAP flap (42) is oriented longitudinally along the medial thigh, while the fleur-de-lis design (43) includes both transverse and vertical components to maximize the amount of donor tissue harvested.

More recently, Dayan and Allen Jr. described a modification of the PAP flap, incorporating the skin paddle design of the DUG flap (44). The diagonal PAP (DPAP) flap is positioned more posteriorly than the DUG, farther away from the lymphatic vessels to the lower extremity but maintains the same flap design oriented along the axis 


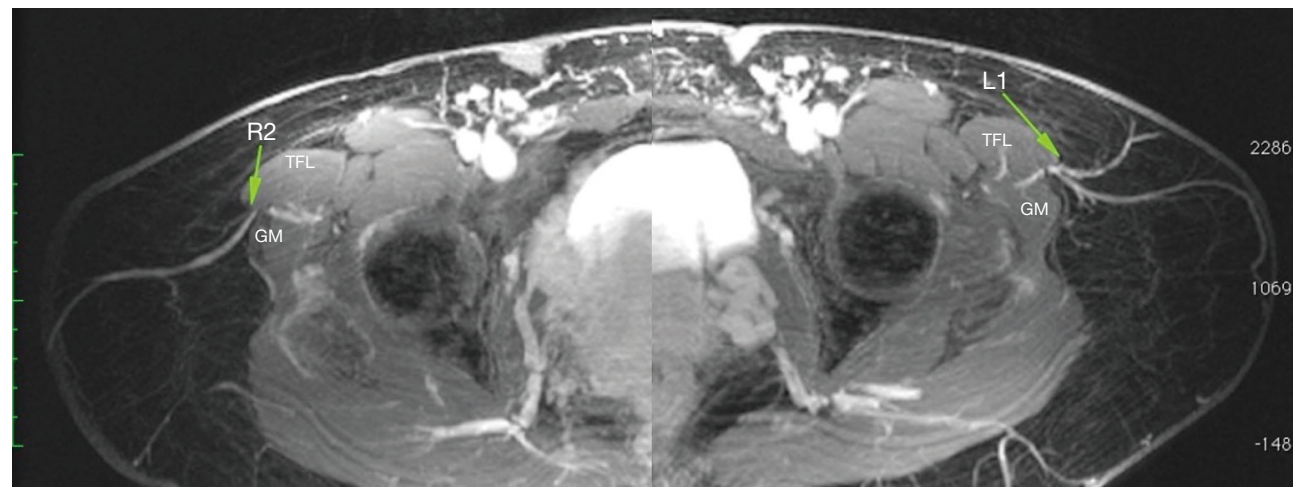

Figure 8 Lateral thigh perforator coursing in the posterior septum between the TFL and GM muscles. TFL, tensor fascia latae; GM, gluteus medius.

of Langer's lines. This orientation allows for a larger skin paddle, decreased tension on closure and avoidance of the scar when sitting; but, like the DUG flap, the scar is more easily visualized on the posterior thigh. Early studies have demonstrated the potential for this flap to be neurotized, coapting the anterior branch of the obturator nerve to the lateral branch of the T4 intercostal nerve (44). Though neurotization has been accomplished in abdominally based free flaps $(45,46)$, this was the first report of an attempt at restoring sensation to thigh-based flaps (44). As microsurgical technique continues to advance and expertise grows, so will this emerging aspect of a complete reconstruction.

\section{Lateral thigh perforator (LTP) or septocutaneous tensor fasciae latae (scTFL) flap}

The LTP flap was initially described as a scTFL flap utilized for coverage of pressure sores, groin reconstruction and lower extremity reconstruction $(47,48)$. Its usage was then broadened to breast reconstruction in 1998 by Allen Sr., who named it the LTP flap after his wife (Linda Truluck Perry) (49). The LTP flap is a reasonable option for small to medium sized breast reconstructions in patients with a "saddlebag" deformity. The LTP flap has a reliable blood supply with adequate vessel caliber. It is located furthest away from the lymphatic drainage basin of the lower extremity, thus eliminating the potential risk of lower extremity lymphedema.

The flap is based on perforators from the ascending lateral circumflex femoral artery, which are frequently found in the septum between the posterior border of the TFL and gluteus medius (GM) muscles and supply the upper lateral thigh (Figure 8). With the patient standing, the saddlebag region is marked. The patient is then placed supine and the following landmarks identified: pubic symphysis, anterior superior iliac spine (ASIS), lateral border of the patella and the greater trochanter. A line is drawn that connects the ASIS to the lateral border of the patella, representing the anterior border of the TFL muscle. A second line is drawn laterally from the pubic symphysis intersecting the anterior TFL border. Perforators are then identified with Doppler ultrasound in the inferolateral quadrant. A pinch test is performed to determine flap width, with flexible orientation (transverse, oblique, S-shaped) of the skin paddle depending on body habitus (Figure 9).

Due to the septocutaneous nature of the perforators, it is a relatively simple dissection. The flap can be harvested via a two-team approach to maximize operative efficiency. The anterior half of the flap is incised first, and dissection proceeds on the superior and inferior borders of the flap until the septum between the TFL and GM muscle is identified (this can be easily identified, as the TFL fascia is thinner with visible muscle fibers underneath, while the GM fascia is thick and white). This is marked for reference and then the anterior half of the flap is elevated from anterior to posterior in the suprafascial plane above the TFL muscle. Musculocutaneous perforators can be ligated with confidence if preoperative imaging has noted a septocutaneous perforator. The septum is approached with caution, and the perforator is identified. At this juncture, the fascia is opened widely and the pedicle dissected back to the takeoff from the lateral circumflex femoral vessels. The pedicle is then divided while the posterior incision remains intact and the flap is perfused through gluteal artery perforators (Figure 10). The remainder of the flap 

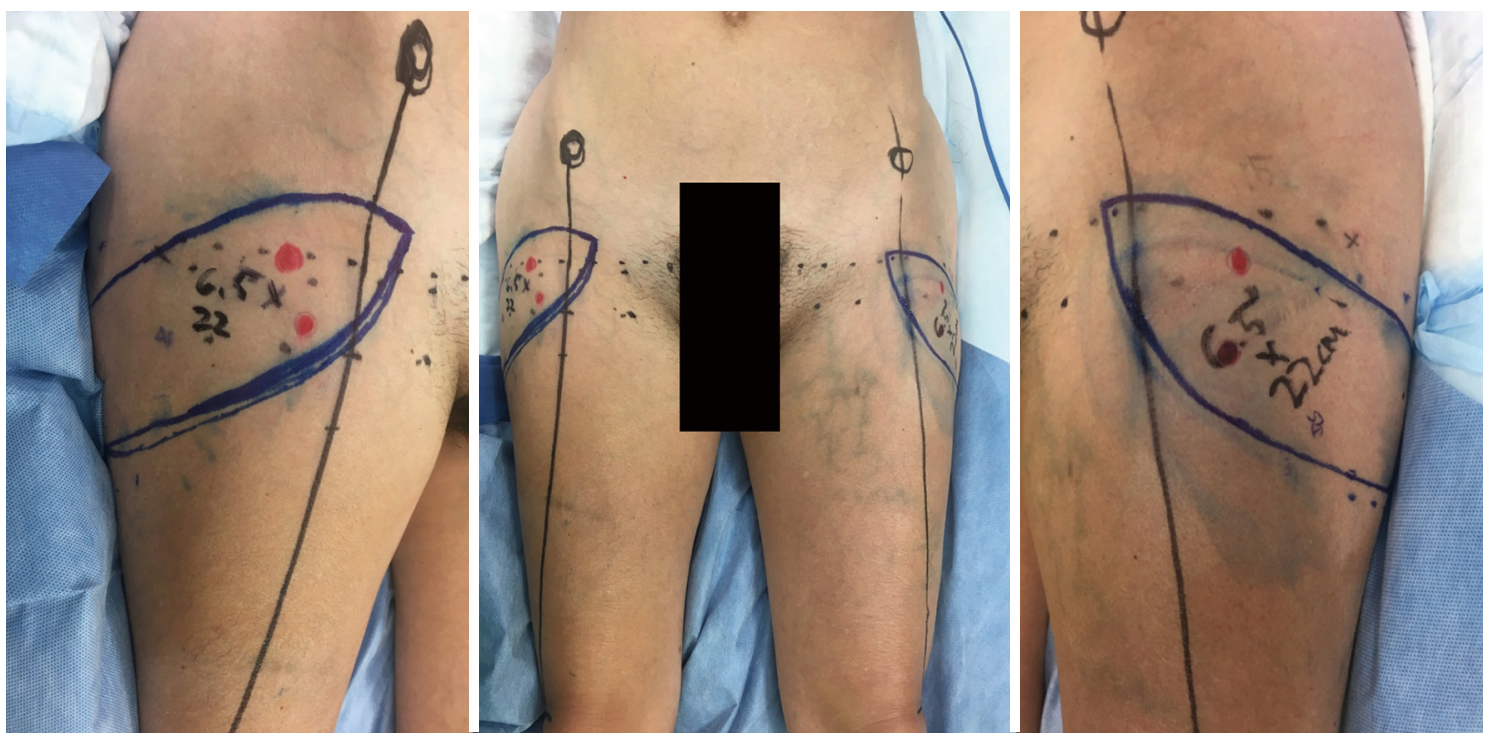

Figure 9 Lateral thigh perforator flap markings. The pubic symphysis, ASIS, lateral border of the patella and the greater trochanter are identified. A line is drawn that connects the ASIS to the lateral border of the patella, representing the anterior border of the TFL muscle. A second line is drawn laterally from the pubic symphysis intersecting the anterior TFL border. Perforators are identified with Doppler ultrasound in the inferolateral quadrant. Flap width is determined by a pinch test. TFL, tensor fascia latae; ASIS, anterior superior iliac spine.
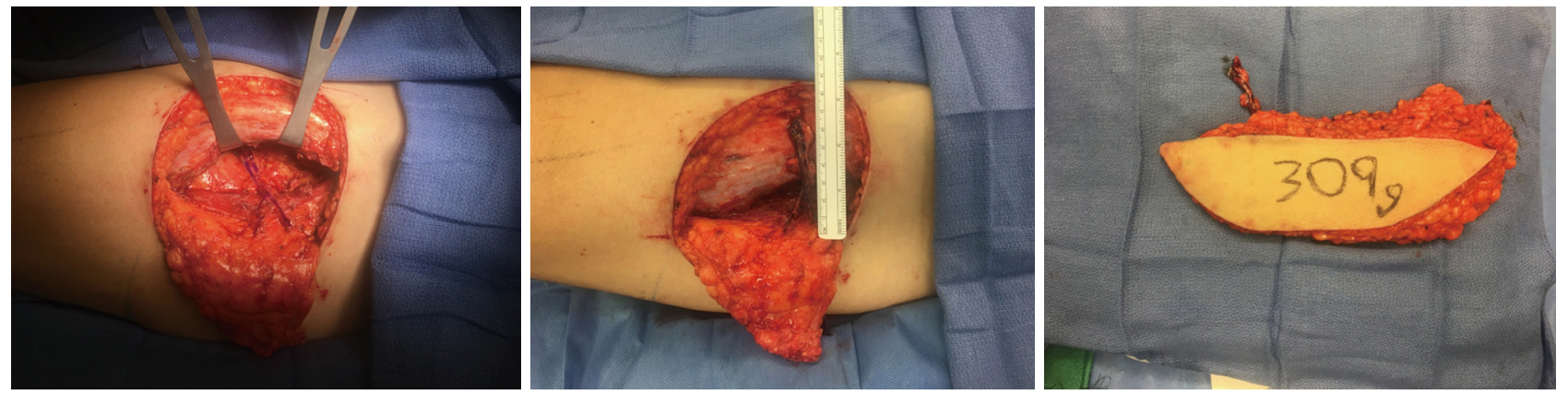

Figure 10 Intraoperative dissection of LTP flap with division of the pedicle prior to making posterior incision. The flap maintains perfusion through posterior gluteal perforators. LTP, lateral thigh perforator.

is then harvested. The perforator location in the flap is relatively eccentric; therefore, an ipsilateral reconstruction is recommended.

A recent prospective analysis performed by Tuinder et al. (50) followed 86 patients with 138 lateral thigh perforator flap breast reconstructions. The median flap weight was $348 \mathrm{~g}$ (range, $175-814 \mathrm{~g}$ ). The authors reported only two total flap losses $(1.4 \%)$, with an $8.0 \%(n=11)$ reexploration rate with successful salvage. The most common complications reported were seroma and infection (9.5\%) followed by wound healing problems (6.3\%). Importantly, the authors advocate for limiting flap width to $6 \mathrm{~cm}$ and the use of quilting sutures to minimize the donor site morbidity.

The limitations of the LTP flap include a small skin paddle and short pedicle. With a larger skin paddle, the natural feminine shape of the thighs can be masculinized (Figure 11), though this can be corrected with strategic liposuction \pm fat grafting. Ultimately, the LTP flap is a useful alternative in the appropriately selected and informed patient, as it does result in a conspicuous scar of the lateral 

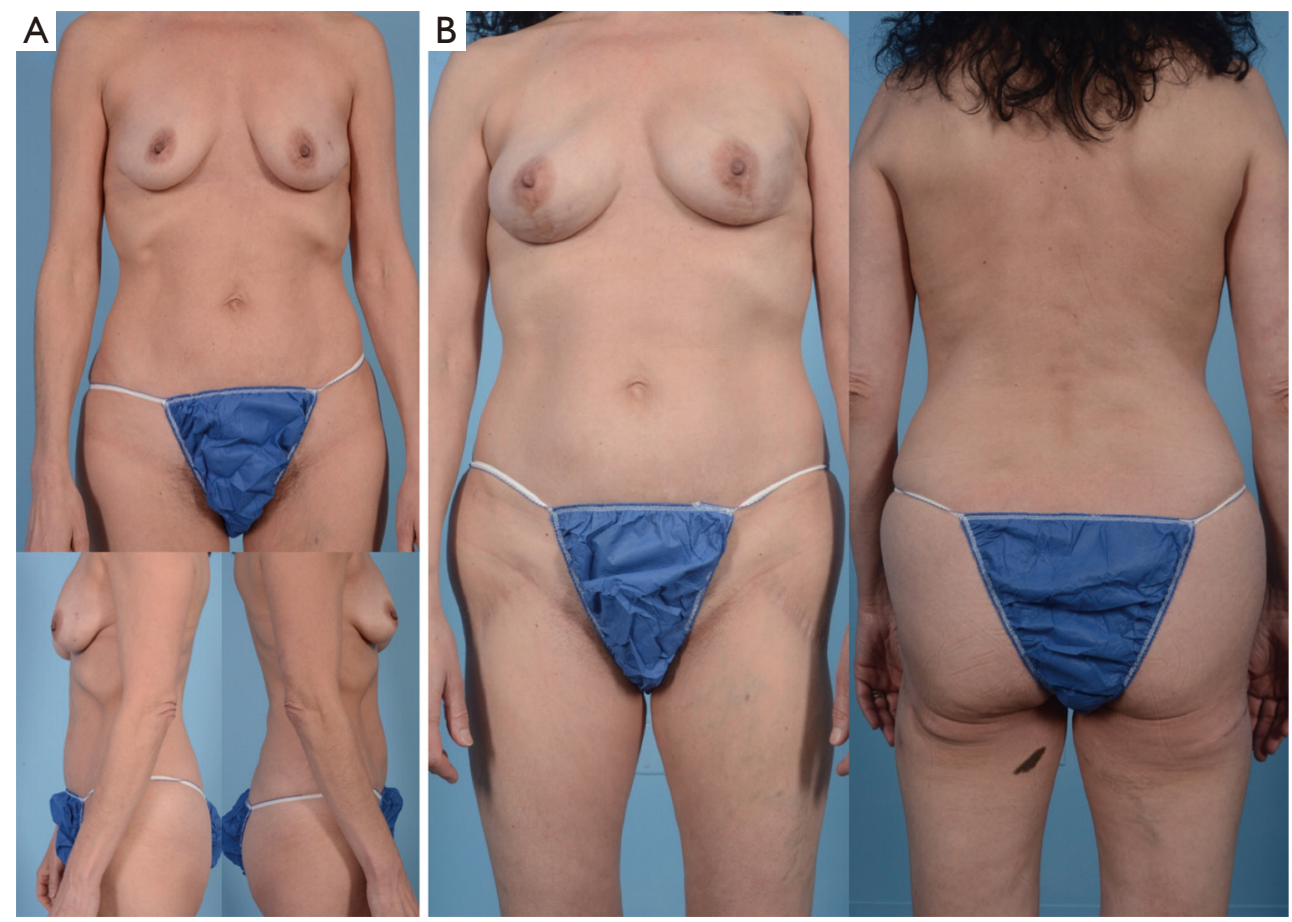

Figure 11 Preoperative (A) and 10-month postoperative (B) photos of bilateral LTP flap reconstruction, without revisions. Note the masculinization of the thighs. LTP, lateral thigh perforator.

thigh.

\section{Trunk flaps}

\section{Lumbar Artery Perforator (LAP) flap}

The LAP flap was initially described as a pedicled flap for covering defects of the dorsal midline or in the lumbosacral area; however, its bulkiness limits its use in these indications (51-53). More recently, this flap has been described for breast reconstruction (54-56). The LAP flap has several advantages. There is consistent pedicle location and ease of elevation. The donor site is appealing for most women as it is easily hidden in clothing, offers large volume with reported softer fat that is more breast-like $(12,56)$ with the potential for anastomosis of sensory nerves (54).

The flap is based on perforating vessels from the lumbar arteries. On each side of the lumbar vertebrae, a lumbar artery originates directly from the aorta then crosses directly behind the psoas major. There are three superior pairs of arteries that run between the erector spinae (ES) and quadratus lumborum (QL) muscles, while an inferior pair runs in front of the QL. The perforators arrive at the skin 5-9 $\mathrm{cm}$ from midline (mean 7.22), with an average of $6 \pm 2$ perforators, and a mean lumbar vessel diameter of $2.1 \mathrm{~mm}$ with pedicle length of $7.0 \pm 3.6$ (57). The flap is designed to capture the soft tissues supplied by these vessels that are commonly referred to as the "love handle" region.

Markings are made with the patient transitioning between lateral decubitus position as well as standing to better access the posterior midline and iliac crest. Ideally, perforators are preoperatively identified with CTA or MRA and then confirmed with Doppler ultrasound. The flap is designed around the perforator with the patient standing to identify the bulkiest excess soft tissue. Care must be taken to assure perforators are captured within the flap! Marking is limited to $3-4 \mathrm{~cm}$ lateral to the posterior midline to avoid skeletonizing the area over the spine and can continue anteriorly to the ASIS. A pinch test is used to determine the width of the flap, generally between 5.5 and $8 \mathrm{~cm}$ (57).

Flap harvest can begin either in the lateral or prone position. It is important to bevel to incorporate the uppermost gluteal fat inferiorly only to avoid deformity at the donor site. The underlying fascia is identified and the flap is raised from anterior to posterior beginning over the external oblique fascia. This portion of the harvest can 
proceed relatively quickly until "glistening" thoracolumbar fascia is encountered. At this location, the lumbar artery perforators are reliably found exiting the fascia. Once the perforator is identified, the pedicle is traced back through the QL and ES paravertebral muscles. Dissection is terminated when the tip of the transverse process of the vertebral body is palpated to avoid injury to spinal nerves and dorsal sensory ganglia, well before the lumbar artery is encountered. The flap harvest is completed, and the donor site is closed in layers over a drain with quilting sutures to avoid seroma.

A large series described by Opsomer $e t a l$. (58) showcased their experience with 100 LAP flaps in 72 patients. They reported a total revision rate of $22 \%$ secondary to hematoma (3\%), venous thrombosis (14\%), and arterial thrombosis $(6 \%)$ with an overall $9 \%$ flap loss. The most common donor site complication was seroma that required aspiration (31\%). Importantly, these authors advocate routine harvesting of the deep inferior epigastric vascular bundle as interposition graft to avoid a lengthy, pedicle dissection and provide a better caliber match between the mammary vessels and the flap pedicle. The requirement of an interposition graft is the main disadvantage of the LAP flap $(12,54,56)$. Nonetheless it is a useful tool in the microsurgical breast reconstruction armamentarium.

\section{Gluteal artery perforator (GAP) flap}

The superior gluteal myocutaneous flap was first described for breast reconstruction by William Shaw in 1983 (59), followed by the inferior gluteal myocutaneous flap in 1989 by Paletta, Bostwick and Nahai (60). Robert Allen Sr. later described superior and inferior gluteal artery perforator (SGAP, IGAP) flaps $(49,61,62)$. This evolution resulted in decreased donor site morbidity while increasing pedicle length (63). The ideal patients have excess tissue in the buttock region compared to the abdomen (64).

The superior gluteal artery (SGA) arises from the internal iliac artery and exits the pelvis superior to piriformis muscle. It enters the gluteus maximus one-third of the distance along the line connecting the posterior superior iliac spine (PSIS) and greater trochanter (64), or approximately $6 \mathrm{~cm}$ below the PSIS and $4.5 \mathrm{~cm}$ lateral to the midline of the sacrum (64). This flap is harvested in the prone position, using a Doppler to identify perforators from SGAP. The skin paddle is marked in oblique pattern from inferior medial to superior lateral, centered on the perforators, with a width of $7-12 \mathrm{~cm}$ (62). After beveling to include subcutaneous fat, the flap is elevated in the subfascial plane from lateral to medial following the orientation of the muscle fibers until an artery and vein of adequate size are reached, with artery size generally being the limiting factor (64).

The inferior gluteal artery is a terminal branch of the internal iliac artery, leaving the pelvis through the sciatic foramen inferior to the piriformis muscle. The artery travels with the greater sciatic nerve, internal pudendal vessels and posterior femoral cutaneous nerve. This generally has a longer pedicle than the SGAP because the course is more oblique. The gluteal fold is marked with the patient standing, and the inferior border of the flap marked $1 \mathrm{~cm}$ inferior and parallel to gluteal fold. The patient is positioned prone for flap harvest, using a Doppler ultrasound to identify perforators. An ellipse is drawn, to include these, roughly parallel to gluteal fold. Allen, Granzow et al. described designing the flap within the inferior gluteal fold to improve donor site contour. In this series, an $8 \mathrm{~cm}$ wide skin paddle can be obtained (64). Flap harvest is similar to SGAP, but fat overlying ischium (usually lighter colored, medial) must be preserved to prevent postoperative discomfort while sitting.

A recent review by Zoccali et al. (65) studied 134 SGAP flaps with an overall complication rate of $37.3 \%$ and a total flap loss rate of $3.7 \%$. The most common flap complication was fat necrosis $(3.7 \%)$ and the most common donor site complication was a contour deformity $(13.7 \%)$ followed by seroma formation (9.7\%). A study from Mirzabeigi et al. (66) reviewed 31 IGAP flaps in 24 patients. They reported a total flap loss rate of $6.5 \%$ with $19 \%$ of patients complaining of sensory deficits. The authors conclude that gluteal perforator flaps are reasonable options for patients who are not candidates from abdominally based reconstruction, though patient selection is imperative.

Though occasionally useful, gluteal flaps have fallen out of favor for several reasons. The patient must change positions between supine and prone, which is inefficient, particularly in immediate cases when working with the surgical oncology team. These flaps also have a short pedicle, necessitating vein grafts, with a technically challenging dissection. There is often recipient vessel size discrepancy and the quality of gluteal soft tissue is much more firm than native breast tissue. Additionally, the IGAP flap risks exposure of sciatic nerve (11). For these reasons, it is the senior author's recommendation that thigh-based flaps are the first line for breast reconstruction when abdominal tissue is not available. 

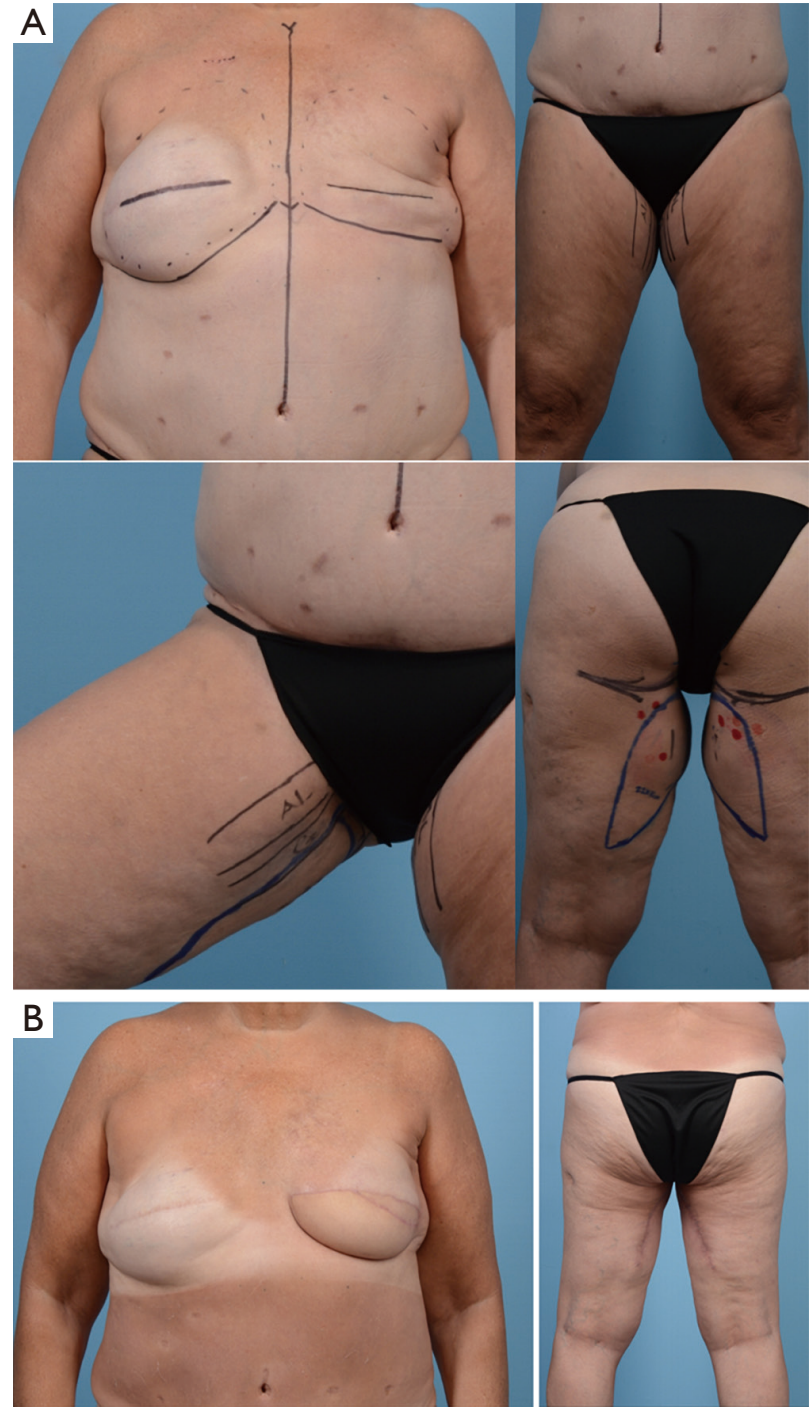

Figure 12 Preoperative (A) and post-operative (B) photographs of a patient with failure of left breast reconstruction presenting for stacked diagonal PAP flap reconstruction. PAP, profunda artery perforator.

\section{Stacked flaps}

Though non-abdominally based free flaps are excellent options for appropriately selected patients undergoing autologous breast reconstruction, these may not provide enough tissue. These flaps tend to have less volume and a smaller skin paddle, inadequate to restore the breast footprint or skin envelope $(67,68)$, especially if the native contralateral breast is large (in the instances of unilateral reconstruction). In this scenario, one solution is to use multiple, or "stacked" flaps in the appropriate patient
$(18,19,69)$. These options include both abdominal and/or non-abdominal flaps (such as from the thighs or buttocks) in order to provide adequate soft tissue for reconstruction (19) (Figure 12).

When deciding to combine multiple flaps for a single defect, there are several options for overcoming the issue of recipient vessels. Currently, the internal mammary vessels in an antegrade fashion are the preferred recipient vessels for microsurgical breast reconstruction, which are typically ligated with direct anastomosis to the flap pedicle in an antegrade fashion. Particularly useful for stacking multiple flaps to a single recipient site is the well-studied reliability of the retrograde system. $(18,19,69)$. In this instance, one flap is anastomosed in the routine, anterograde fashion while the other is then anastomosed to the caudal IMA/ IMV retrograde system (Figure 13). A second option for stacking flaps often employed is the "daisy-chain" technique, anastomosing the second flap to a branch of the pedicle of the first flap. Although this technique of flaps in series may seem appealing in that only one pair of recipient vessels are needed (70), using the internal mammary vessels both anterograde and retrograde is often preferred. These vessels are likely to have a better size match to the pedicle and offer a layer of protection against the second flap, if one should develop thrombosis. Finally, a third option of anastomoses can be performed to two separate recipient systems. In the case of breast reconstruction, this involves utilizing the thoracodorsal vessels in addition to the internal mammary vessels (11), though this is less common. When "stacking" flaps, it is important to know that combining multiple flaps for a single reconstructive endeavor is technically challenging but can be performed within an acceptable time frame and complication profile (19) in the hands of a proficient surgical team. All efforts for operative efficiency need to be maximized to make these procedures accessible for routine reconstruction (18).

\section{Conclusions}

While abdominally based free tissue transfer remains the gold standard for autologous breast reconstruction, there are several robust and well-studied options for flap options of the thigh and trunk. The limitations of the thighbased flaps (i.e., gracilis, PAP and LTP flaps) include a lack of adequate volume for a single flap to provide, often necessitating "stacking" flaps to achieve the desired result. Additionally, scar placement can be challenging in that it can be conspicuous and/or painful while sitting. Trunk- 

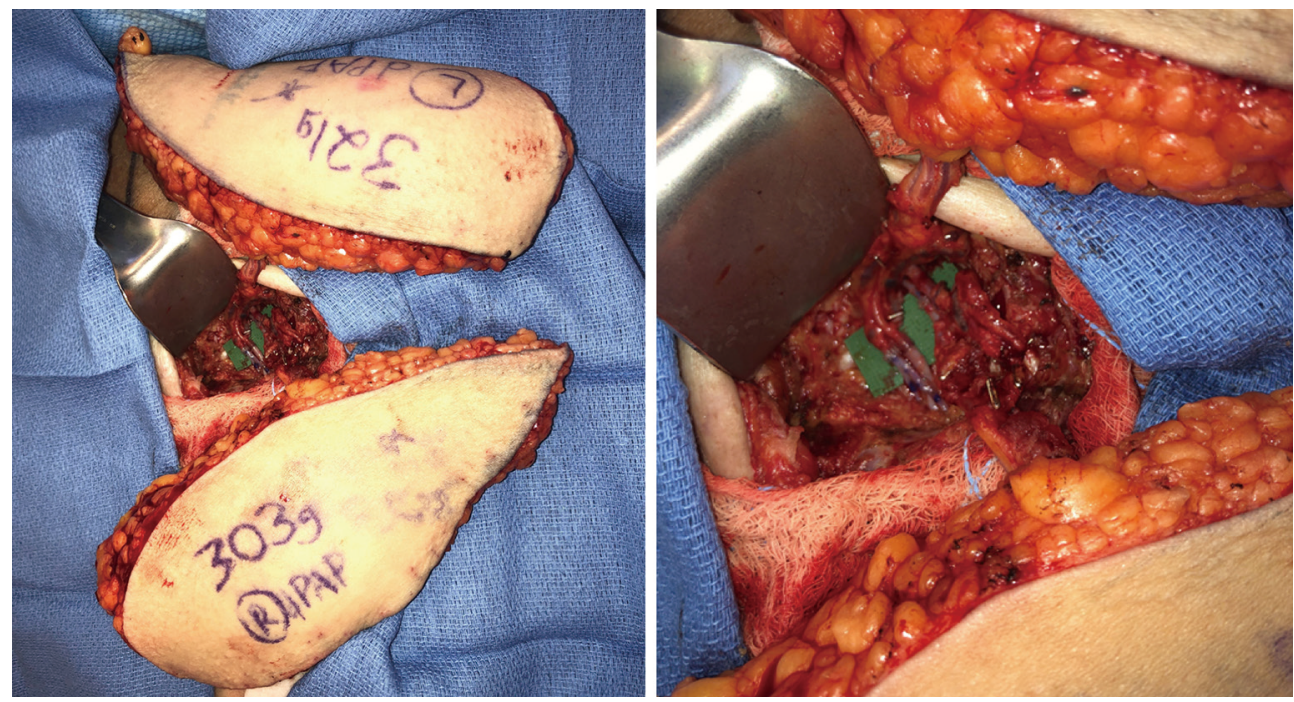

Figure 13 Intraoperative photograph of stacked DPAP flaps with retrograde and anterograde anastomoses. DPAP, diagonal profunda artery perforator.

based flaps (SGAP/IGAP, LAP) are also reasonable options though with significant limitations. These flaps have short pedicles that commonly require vein grafts. Additionally, the surgery requires position changes, which is timeconsuming.

With further innovation in reconstructive microsurgery, new avenues are being explored to enhance autologous breast reconstruction. Neurotization of free flaps, both from the abdomen (46) and thigh (44) have been reported and will continue to undergo surgical refinements to improve success. Vascularized lymph node transfer (VLNT) (71) and lymphovenous anastomosis (LVA) (72) are also emerging techniques for the surgical management of lymphedema. In the breast cancer patient, this may be performed for the treatment of extremity lymphedema or even a prophylactic procedure for the high-risk patient (axillary dissection with radiation therapy) (73). Additionally, patient reported outcome measures and cost control are the new frontiers of surgical quality improvement and will continue to grow with further research (74).

Ultimately, the decision for breast reconstruction is a personal one. For those patients that choose to undergo autologous reconstruction, there are many options. The DIEP flap remains the gold standard; however, alternate flaps from the thighs or trunk can provide an excellent option for breast reconstruction in the appropriately selected patient. It is the knowledge and clinical skill of the reconstructive microsurgeon that can make this a reality for almost any patient.

\section{Acknowledgments}

Funding: None.

\section{Footnote}

Provenance and Peer Review: This article was commissioned by the Guest Editors (Charles E Butler, Carrie Chu, and Margaret Roubaud) for the series "New Frontiers in Breast Reconstruction" published in Gland Surgery. The article was sent for external peer review organized by the Guest Editors and the editorial office.

Conflicts of Interest: All authors have completed the ICMJE uniform disclosure form (available at http://dx.doi. org/10.21037/gs.2020.03.16). The authors have no conflicts of interest to declare.

Ethical Statement: The authors are accountable for all aspects of the work in ensuring that questions related to the accuracy or integrity of any part of the work are appropriately investigated and resolved.

Open Access Statement: This is an Open Access article distributed in accordance with the Creative Commons Attribution-NonCommercial-NoDerivs 4.0 International 
License (CC BY-NC-ND 4.0), which permits the noncommercial replication and distribution of the article with the strict proviso that no changes or edits are made and the original work is properly cited (including links to both the formal publication through the relevant DOI and the license). See: https://creativecommons.org/licenses/by-nc$\mathrm{nd} / 4.0 \%$.

\section{References}

1. Albornoz CR, Bach PB, Mehrara BJ, et al. A paradigm shift in U.S. breast reconstruction: increasing implant rates. Plast Reconstr Surg 2013;131:15-23.

2. Avraham T, Clavin N, Mehrara BJ. Microsurgical breast reconstruction. Cancer J 2008;14:241-7

3. Yueh JH, Slavin SA, Adesiyun T, et al. Patient satisfaction in postmastectomy breast reconstruction: a comparative evaluation of DIEP, TRAM, latissimus flap, and implant techniques. Plast Reconstr Surg 2010;125:1585-95.

4. Hartrampf CR, Soneflan M, Black PW. Breast reconstruction with a transverse abdominal island flap. Plast Reconstr Surg 1982;69:216-25.

5. Grotting JC, Urist MM, Maddox WA, et al. Conventional TRAM flap versus free microsurgical TRAM flap for immediate breast reconstruction. Plast Reconstr Surg 1989;83:828-41.

6. Holmström $\mathrm{H}$. The free abdominoplasty flap and its use in breast reconstruction. An experimental study and clinical case report. Scand J Plast Reconstr Surg 1979;13:423-27

7. Seth AK, Allen RJ Jr. Modern techniques and alternative flaps in microsurgical breast reconstruction. J Surg Oncol 2018;118:768-79.

8. Allen RJ, Treece P. Deep inferior epigastric perforator flap for breast reconstruction. Ann Plast Surg 1994;32:32-8.

9. Healy C, Allen RJ Sr. The evolution of perforator flap breast reconstruction: twenty years after the first DIEP flap. J Reconstr Microsurg 2014;30:121-5.

10. Koshima I, Soeda S. Inferior epigastric artery skin flaps without rectus abdominis muscle. Br J Plast Surg 1989;42:645-8.

11. Patel NG, Ramakrishnan V. Microsurgical Tissue Transfer in Breast Reconstruction. Clin Plast Surg 2017;44:345-59.

12. Mujtaba B, Hanafy AK, Largo RD, et al. The lumbar artery perforator flap: clinical review and guidance on image reporting. Clin Radiol 2019;74:756-62.

13. Agrawal MD, Thimmappa ND, Vasile JV, et al. Autologous breast reconstruction: preoperative magnetic resonance angiography for perforator flap vessel mapping. J Reconstr
Microsurg 2015;31:1-11.

14. Greenspun D, Vasile J, Levine J, et al. Anatomic imaging of abdominal perforator flaps without ionizing radiation: seeing is believing with magnetic resonance imaging angiography. J Reconstr Microsurg 2010;26:37-44.

15. Lee JS, Patel KM, Zou Z, et al. Computerized tomographic and magnetic resonance angiography for perforator- based free flaps: technical considerations. Clin Plast Surg 2011;38:219-28.

16. Rosson GD, Shridharani SM, Magarakis M, et al. Threedimensional computed tomographic angiography to predict weight and volume of deep inferior epigastric artery perforator flap for breast reconstruction. Microsurgery 2011;31:510-6.

17. Rha EY, Choi IK, Yoo G. Accuracy of the method for estimating breast volume on three-dimensional simulated magnetic resonance imaging scans in breast reconstruction. Plast Reconstr Surg 2014;133:14-20.

18. Stalder MW, Lam J, Allen RJ, et al. Using the retrograde internal mammary system for stacked perforator flap breast reconstruction: 71 breast reconstructions in 53 consecutive patients. Plast Reconstr Surg 2016;137:265e-77e.

19. Mayo JL, Allen RJ, Sadeghi A. Four-flap breast reconstruction: bilateral stacked DIEP and PAP flaps. Plast Reconstr Surg Glob Open 2015;3:e383.

20. Azuma R, Morimoto Y, Masumoto K, et al. Detection of skin perforators by indocyanine green fluorescence nearly infrared angiography. Plast Reconstr Surg 2008;122:1062-7.

21. Duggal CS, Madni T, Losken A. An outcome analysis of intraoperative angiography for postmastectomy breast reconstruction. Aesthet Surg J 2014;34:61-5.

22. Pestana IA, Zenn MR. Correlation between abdominal perforator vessels identified with preoperative CT angiography and intraoperative fluorescent angiography in the microsurgical breast reconstruction patient. Ann Plast Surg 2014;72:S144-9.

23. Yousif NJ, et al. The transverse gracilis musculocutaneous flap. Ann Plast Surg 1992;29:482-90.

24. Arnez ZM, Pogorelec D, Planinsek F, et al. Breast reconstruction by the free transverse gracilis (TUG) flap. Br J Plast Surg 2004;57:20-6.

25. Dayan JH, Allen RJ Jr. Lower Extremity Free Flaps for Breast Reconstruction. Plast Reconstr Surg 2017;140:77S-86S.

26. An X, Yue B, Lee JH, et al. Arterial anatomy of the gracilis muscle as determined by latex injection and glycerin transparency. Clin Anat 2012;25:231-4.

27. Magden O, Tayfur V, Edizer M, et al. Anatomy of gracilis 
muscle flap. J Craniofac Surg 2010;21:1948-50.

28. Schoeller T, Huemer GM, Wechselberger G. The transverse musculocutaneous gracilis flap for breast reconstruction: guidelines for flap and patient selection. Plast Reconstr Surg 2008;122:29-38.

29. Schoeller T, Wechselberger G. Breast reconstruction by the free transverse gracilis (TUG) flap. Br J Plast Surg 2004;57:481-2.

30. Craggs B, Vanmierlo B, Zeltzer A, et al. Donor site morbidity following harvest of the transverse myocutaneous gracilis ap for breast reconstruction. Plast Reconstr Surg 2014;134:682e-91e.

31. Fansa H, Schirmer S, Warnecke IC, et al. The transverse myocutaneous gracilis muscle flap: a fast and reliable method for breast reconstruction. Plast Reconstr Surg 2008;122:1326-33.

32. Pülzl P, Schoeller T, Kleewein K, et al. Donor site morbidity of the transverse musculocutaneous gracilis flap in autologous breast reconstruction: short-term and longterm results. Plast Reconstr Surg 2011;128:233e-42e.

33. Saint-Cyr M, Wong C, Oni G, et al. Modifications to extend the transverse upper gracilis flap in breast reconstruction: clinical series and results. Plast Reconstr Surg 2012;129:24e-36e.

34. Dayan E, Smith ML, Sultan M, et al. The Diagonal Upper Gracilis (DUG) Flap A Safe and Improved Alternative to the TUG Flap. Plast Reconstr Surg 2013;132:33-4.

35. Allen RJ, Haddock NT, Ahn CY, et al. Breast reconstruction with the profunda artery perforator flap. Plast Reconstr Surg 2012;129:16e-23e.

36. Hurwitz DJ, Walton RL. Closure of chronic wounds of the perineal and sacral regions using the gluteal thigh flap. Ann Plast Surg 1982;8:375-86.

37. Angrigiani C, Grilli D, Thorne CH. The adductor flap: a new method for transferring posterior and medial thigh skin. Plast Reconstr Surg 2001;107:1725-31.

38. Song YG, Chen GZ, Song YL. The free thigh flap: a new free flap concept based on the septocutaneous artery. Br J Plast Surg 1984;37:149-59.

39. Ahmadzadeh R, Bergeron L, Tang M, et al. The posterior thigh perforator flap or profunda femoris artery perforator flap. Plast Reconstr Surg 2007;119:194-200; discussion 201-2.

40. Allen RJ Jr, Lee ZH, Mayo JL, et al. The Profunda Artery Perforator Flap Experience for Breast Reconstruction. Plast Reconstr Surg 2016;138:968-75.

41. Haddock NT, Gassman A, Cho MJ, et al. 101 Consecutive Profunda Artery Perforator Flaps in Breast Reconstruction:
Lessons Learned with Our Early Experience. Plast Reconstr Surg 2017;140:229-39.

42. Rivera-Serrano CM, Aljaaly HA, Wu J, et al. Vertical PAP Flap: Simultaneous Longitudinal Profunda Artery Perforator Flaps for Bilateral Breast Reconstructions. Plast Reconstr Surg Glob Open 2017;5:e1189.

43. Saussy K, Stalder MW, Delatte SJ, et al. The Fleur-dePAP Flap for Bilateral Breast Reconstruction. J Reconstr Microsurg Open 2017;02:e1-3.

44. Dayan JH, Allen RJ Jr. Neurotized Diagonal Profunda Artery Perforator Flaps for Breast Reconstruction. Plast Reconstr Surg Glob Open 2019;7:e2463.

45. Beugels J, Cornelissen AJM, van Kuijk SMJ, et al. Sensory Recovery of the Breast following Innervated and Noninnervated DIEP Flap Breast Reconstruction. Plast Reconstr Surg 2019;144:178e-88e.

46. Spiegel AJ, Menn ZK, Eldor L, et al. Breast reinnervation: DIEP neurotization using the third anterior intercostal nerve. Plast Reconstr Surg Glob Open 2013;1:e72.

47. Hill HL, Nahai F, Vasconez LO. The tensor fascia lata myocutaneous free flap. Plast Reconstr Surg 1978;61:517-22.

48. Nahai F, Silverton JS, Hill HL, et al. The tensor fascia lata musculocutaneous flap. Ann Plast Surg 1978;1:372-9.

49. Allen R, Guarda H, Wall F, et al. Free flap breast reconstruction: the LSU experience (1984-1996). J La State Med Soc 1997;149:388-92.

50. Tuinder SMH, Beugels J, Lataster A, et al. The Lateral Thigh Perforator Flap for Autologous Breast Reconstruction: A Prospective Analysis of 138 Flaps. Plast Reconstr Surg 2018;141:257-68.

51. Ao M, Mae O, Namba Y, et al. Perforator-based flap for coverage of lumbosacral defects. Plast Reconstr Surg 1998;101:987-91.

52. Bostwick J III, Scheflan M, Nahai F, et al. The "reverse" latissimus dorsi muscle and musculocutaneous flap: Anatomical and clinical considerations. Plast Reconstr Surg 1980;65:395-9.

53. Roche NA, Van Landuyt K, Blondeel PN, et al. The use of pedicled perforator flaps for reconstruction of lumbosacral defects. Ann Plast Surg 2000;45:7-14.

54. de Weerd L, Elvenes OP, Strandenes E, et al. Autologous breast reconstruction with a free lumbar artery perforator flap. Br J Plast Surg 2003;56:180-3.

55. Hamdi M, Craggs B, Brussaard C, et al. Lumbar artery perforator flap: An anatomical study using multidetector computed tomographic scan and surgical pearls for breast reconstruction. Plast Reconstr Surg 2016;138:343-52. 
56. Peters KT, Blondeel PN, Lobo F, et al. Early experience with the free lumbar artery perforator flap for breast reconstruction. J Plast Reconstr Aesthet Surg 2015;68:1112-9.

57. Kato H, Hasegawa M, Takada T, et al. The lumbar artery perforator based island flap: anatomical study and case reports. Br J Plast Surg 1999;52:541-6.

58. Opsomer D, Stillaert F, Blondeel PN, et al. The Lumbar Artery Perforator Flap in Autologous Breast Reconstruction: Initial Experience with 100 Cases. Plast Reconstr Surg 2018;142:1e-8e.

59. Shaw, WW. Breast reconstruction by superior gluteal microvascular free flaps without silicone implants. Plast Reconstr Surg 1983;72:490-501.

60. Paletta CE, Bostwick J, Nahai F. The inferior gluteal free flap in breast reconstruction. Plast Reconstr Surg 1989;84:875-83; discussion 884-5.

61. Allen RJ, Tucker C Jr. Superior gluteal artery perforator free flap for breast reconstruction. Plast Reconstr Surg 1995;95:1207-12.

62. LoTempio MM, Allen RJ. Breast reconstruction with SGAP and IGAP flaps. Plast Reconstr Surg 2010;126:393-401.

63. Gagnon AR, Blondeel PN. Superior Gluteal Artery Perforator Flap. Semin Plast Surg 2006;20:79-88.

64. Granzow JW, Levine JL, Chiu ES, et al. Breast reconstruction with gluteal artery perforator flaps. J Plast Reconstr Aesthet Surg 2006;59:614-21.

65. Zoccali G, Mughal M, Giwa L, et al. Breast reconstruction with Superior Gluteal Artery Perforator free flap: 8 years of experience. J Plast Reconstr Aesthet Surg 2019;72:1623-31.

66. Mirzabeigi MN, Au A, Jandali S, et al. Trials and

Cite this article as: Myers PL, Nelson JA, Allen RJ Jr. Alternative flaps in autologous breast reconstruction. Gland Surg 2021;10(1):444-459. doi: 10.21037/gs.2020.03.16 tribulations with the inferior gluteal artery perforator flap in autologous breast reconstruction. Plast Reconstr Surg 2011;128:614e-24e.

67. Blondeel PN, Hijjawi J, Depypere H, et al. Shaping the breast in aesthetic and reconstructive breast surgery: an easy three-step principle. Plast Reconstr Surg 2009;123:455-62.

68. Blondeel PN, Hijjawi J, Depypere H, et al. Shaping the breast in aesthetic and reconstructive breast surgery: an easy three-step principle. Part II-Breast reconstruction after total mastectomy. Plast Reconstr Surg 2009;123:794-805.

69. Salgarello M, Visconti G, Barone-Adesi L, et al. The retrograde limb of internal mammary vessels as reliable recipient vessels in DIEP flap breast reconstruction: a clinical and radiological study. Ann Plast Surg 2015;74:447-53.

70. Koolen PGL, Lee BT, Lin SJ, et al. Bipedicle conjoined perforator flaps in breast reconstruction. J Surg Res 2015;197:256-64.

71. Schaverien MV, Badash I, Patel KM, et al. Vascularized Lymph Node Transfer for Lymphedema. Semin Plast Surg 2018;32:28-35.

72. Garza RM, Chang DW. Lymphovenous bypass for the treatment of lymphedema. J Surg Oncol 2018;118:743-9.

73. Dayan JH, Ly CL, Kataru RP, et al. Lymphedema: Pathogenesis and Novel Therapies. Annu Rev Med 2018;69:263-76.

74. Sharma K, Steele K, Birks M, et al. Patient-Reported Outcome Measures in Plastic Surgery: An Introduction and Review of Clinical Applications. Ann Plast Surg 2019 Sep;83:247-52. 